\title{
Improving the Quality of Social, Cultural and Humanitarian Education in Modern Universities: A Discourse
}

Askadula Sabirov ${ }^{+*}$ and Lilya Sabirova ${ }^{i}$

\section{Abstract}

A teacher plays a vital role in improving the quality of social, cultural and humanitarian (SCH) education. He/she channels and corrects students when they take steps towards a specific goal, delivers knowledge, manages the learning process, and shapes behavioural patterns. This research aims to contribute to the improvement of $\mathrm{SCH}$ education quality in modern universities. The study was carried out with the participation of 790 students from 7 universities: Moscow Institute of Physics and Technology, the Moscow Engineering Physics Institute, the Russian Presidential Academy of National Economy and Public Administration (Moscow), the Moscow State Institute of Steel and Alloys, the Moscow Power Engineering Institute, the Voronezh State University, and the North-Eastern Federal University (Yakutsk). The survey reveals uncongenial findings: $30 \%$ of the respondents are satisfied with the quality of $\mathrm{SCH}$ education in their university, $67 \%$ are unsatisfied, and $3 \%$ are not sure. The findings allow teachers of humanities and social studies to apply the mechanism described in this study in educational contexts. This research tackles the Elabuga model of education quality improvement in the context of various universities and institutes. The research shows that the Elabuga teaching model has improved the quality of students majoring in humanities and social studies and led to a qualitative and frequent use of innovative methods. Thus, from the US and Russian experience in socio-cultural and humanitarian education, it is evident that Humanities and Social Studies will be more in line with Science and Engineering in years to come.

Keywords: Socio-Cultural and Humanitarian Education; Social Design; Learning Process Monitoring; Sociologist Job; Professional Competences

\footnotetext{
${ }^{\dagger}$ Kazan Federal University, Russian Federation

*Corresponding Author, Email: sascadula@yahoo.com, agsabir@list.ru

ÎSenior Lecturer of Philosophy and Sociology Department, Kazan Federal University, Russian Federation, Email: slilja2006@rambler.ru

(C) 2019 Sabirov \& Sabirova. This is an Open Access article distributed under the terms of the Creative Commons Attribution License (http://creativecommons.org/licenses/by/2.0), which permits unrestricted use, distribution, and reproduction in any medium, provided the original work is properly cited.
} 


\section{Introduction}

In developing countries, socio-cultural and humanitarian $(\mathrm{SCH})$ education experiences a crisis (Bouvier, 2012; Levitz \& Belkin, 2013; Vyazemsheva, 2016; Akimova et al., 2019) and are less popular among students considering the struggle with employment after graduating (Levitz \& Belkin, 2013). This crisis is a consequence of non-compliance with $\mathrm{SCH}$ education requirements imposed by a superindustrial society (Teichler, 2003; Toffler, 2003). The super-industrial or post-industrial society is a society going through automation, globalisation and digitalisation processes that occur in the field of production (Berglund et al., 2019). The automation process may displace people from the manufacturing sector to spheres like households, sports and services. In such a climate, a person will have to perform not within the human-nature and humantechnology systems but the human-human system. The overall digitalisation demands a person to form skills of self-reflection, request statement and information processing (Ashmarina et al., 2020). Globalisation in education forces a person to handle multilingual and multicultural platforms, as well as to engage in cross-border communication (Naz, 2019). Therefore, humanitarian knowledge gains importance. Barring the boosting effect of humanities on narrative skills, humanitarian disciplines, as specific social practices. To address the problem of crisis that affects humanitarian knowledge, one needs to answer the question: are all humanitarian disciplines able to foster self-reflection skills in the same way as history and the sociology of science? A person must possess competencies like teamwork and social tolerance. In this regard, university $\mathrm{SCH}$ education requires reforming to achieve them. In particular, B. Readings (1995) and S. During (2004) consider the advanced practice of conducting interdisciplinary cultural studies a symptom of such a crisis. During (2004) believes that preserving the disciplinary structure of humanitarian knowledge reproduction is no longer as relevant as the problem of maintaining its attractiveness and openness to changing demands. This statement is agreeable, but the suggestion to maintain "attractiveness and openness" will not solve the problem of disciplinary mediation. Such a decision would automatically lead to the abolition of the institutional basis of humanitarian knowledge, as evidenced by Craig Calhoun (2005).

The quality of $\mathrm{SCH}$ education moves towards better, and while the movement takes place, universities produce new strategies for education development (Toffler, 2003), related priorities (Barber et al., 2013; Rubtcova \& Pavenkov, 2019), and methods for drawing attention to non-technical disciplines (Abeles, 2011). This list also includes competencies that permit individuals to analyse their own actions from social, cultural, economic and environmental points of view (Rickmann, 2017). These competencies also allow analysing the potential of $\mathrm{SCH}$ disciplines for identifying directions in which societies move (Rickmann, 2017). Specialists in SCH education strive to shape an education system by the year 2030 (Bouvier, 2012).

To accomplish this intention, they propose redefining $\mathrm{SCH}$ education with the necessary time-demanded competencies (Lönnblad \& Vartiainen, 2012; Reynolds, 2019) like communication, innovation, self-regulation, and philosophical reasoning. There is also a suggestion to tie $\mathrm{SCH}$ programmes to advances that emerge in social and humanitarian science (European Commission, 2003). SCH programmes require the introduction of new courses (Long, 2013). The current trends in $\mathrm{SCH}$ education involve the use of practice-oriented approach (Piirainen et al., 2016), human capital enhancement (Fadel, 2012), the "humanisation" of teacher-student relationship (Kitova, 2018: 63), and innovations (Yeralina, 2017). The research begins with a review of the literature. Following this, it outlines the methods deployed. It then goes to critically discuss the results of the research. 


\section{Literature Review}

In 2008, Webb conducted a comparative study between the minimum number of required humanities and socio-cultural science credits for graduation at top-tier undergraduate universities in the USA and similar Englishmedium universities in the Arabian Gulf, and found that a significant difference exists between top tier undergraduate engineering programs in the USA and similar programs in the Arabian Gulf. Typically, most arguments in favour of the humanities seek to establish a definite link between successful engineering practice and a minimum level of understanding of the type provided in humanities courses. For example, it has been claimed that by consolidating communication skills and exposing students to alternative discourses and understandings, humanities courses help to address the marginalisation of engineers to technical pursuits outside the decision-making process while also stimulating creativity. It also gives students the opportunity for self-reflection that the humanities usually provides for.

One more positive trait of the humanities in engineering is that it may attract more potential students of different qualities. Finally, there is the view that the knowledge instantiated within the humanities is necessary to the civic and moral development of students. Pohoryles and Schadauer (2009: 156) argue that "the future of the socio-cultural sciences and the humanities depends on two interrelated dimensions: the development of the disciplinary state of the art and openness towards other disciplines, stakeholders and the society at large".

Socio-cultural sciences and the humanities have an important mission in the formation of the knowledge economy and society and evidencebased politics (Jovchelovitch, 2019). However, "there are discrepancies between the potential importance of social science knowledge and the comparatively low attention they receive from politics, other research communities and the public as a whole. The future of the sociocultural sciences and humanities depends on their ability better to meet the needs of societies" (Pohoryles and Schadauer, 2009: 159).

\section{Methods}

This study investigates a model for education quality improvement that was first utilised in the Elabuga Institute of Kazan Federal University (Russia) under the government contract for practice-oriented and competency-based $\mathrm{SCH}$ education in 2014-2017. The investigation takes place in the context of various universities and institutions. The contractual programme or education model follows those of the leading universities like the Oxford Brookes University (UK), the Higher School of Economics (Russia), the Kazan Federal University (Russia), the National Institute of Education (Singapore), and the Massachusetts Institute of Technology (USA). The main aims of the program were as follows:

- Identifying educational effectiveness factors important for $\mathrm{SCH}$ education;

- Creating and implementing professional development programs and materials for $\mathrm{SCH}$ education in order to improve their teaching practice.

To explore the current state-of-the-art in $\mathrm{SCH}$ education and possibilities for improving its quality, a questionnaire survey was conducted among Russian university students. This longitudinal survey follows first-year and second-year students, who enrolled in science and humanitarian courses, over the period between 2014 and 2017. The survey covers the educational process organisation; information sources utilised in lesson preparation (department library, other libraries, the Internet); motives and choice factors; choice characterisation (right/wrong to choose the specified department); expectation delivery; preferred fields of activity after graduation, and student opinion on cheating in learning. Out of the initial sample of 1400 students, only 790 students signed the consent form ( $64 \%$ females and $36 \%$ males at the age of 16 to 18$)$. Statistical data processing is performed with the SPSS Statistics v17.0. The statistical error is below $3 \%$. The research was conducted with the participation of the IREG Observatory on Academic Ranking and Excellence, which accepted the responsibility of performing 
university surveys, collecting scientometric indicators and data from the public domain. The equality of $\mathrm{SCH}$ education in Russian is compared with that abroad in terms of criteria, such as general and specific lines of education quality improvement; common and specific features of strategies for education quality improvement. To investigate the effect of the Elabuga education model, it was applied in a number of universities as part of an experiment. The sample of survey universities includes the Moscow Institute of Physics and Technology, the Moscow Engineering Physics Institute, the Russian Presidential Academy of National Economy and Public Administration, the Moscow State Institute of Steel and Alloys, the Moscow Power Engineering Institute, the Voronezh State University, and the North-Eastern Federal University. The student participants form an experimental group (400 students) and a control group (390 students). Students from the control group were learning the standard education programme (system approach) (Teichler, 2003), whereas students from the experimental group were learning using the Elabuga education model. The inclusion criterion was the mode of thinking:

- Intuitive Thinkers or right-brain subjects with emotions over logic from a control group;

- Analytical Thinkers or left-brain subjects with logic over emotions form an experimental group.

Both programmes boost none of the thinking styles. Therefore, tests in the ascertaining experiment cover this factor.

During the second stage of experiment or simulation, students in the control group had their components of professional thinking (logical and creative) developing unintentionally to teaching competencies. By contrast, the experimental group was learning under the programme that provides for meaningful development of thinking. The learning settings can be described as follows:

creative and logical thinking is shaped, developed and integrated in a stepwise manner through the system and activity-based approaches, creative and professional orientation of the learning process;

content and technology of professional thinking development are student-based and are put into practical context by the following provisions: subject-driven content, focus on selfdevelopment and self-education, individual development trajectory, progress monitoring.

The first or standard learning setting follows the principle of a system approach. This means that learning courses are organised in a bottom-up manner; semantic units of the course content are differentiated; learning content and technology are both optimised, etc.

\section{Results}

In post-Soviet countries, $\mathrm{SCH}$ education serves purposes other than fulfilling the social demand. Therefore, universities may want to reconsider $\mathrm{SCH}$ education specifically, from the interdisciplinary point of view. This research contributes to the improvement of the $\mathrm{SCH}$ education quality by identifying a corresponding model. This model comprises an integrated set of specific methods, procedures, technologies and actions that allow improving the quality of $\mathrm{SCH}$ education. The problem scale analysis reveals some meaningful options of system approaches and concepts that touch each sphere of reality at each level (macro-, mesoand micro-levels).

Modern science is challenged with processing the accumulated amount of diverse facts, theories and methods concerning the system approach. The fundamental ontological grounds of sociality can be determined only if theoretical and methodological data on GST and the general principles of the system approach are outlined. The same is required for theoretical and methodological principles of the General Theory of Society.

The survey provides different answers to the question:"Are you satisfied with the quality of socio-cultural and humanitarian education in your university?" (see, Figure 1). 

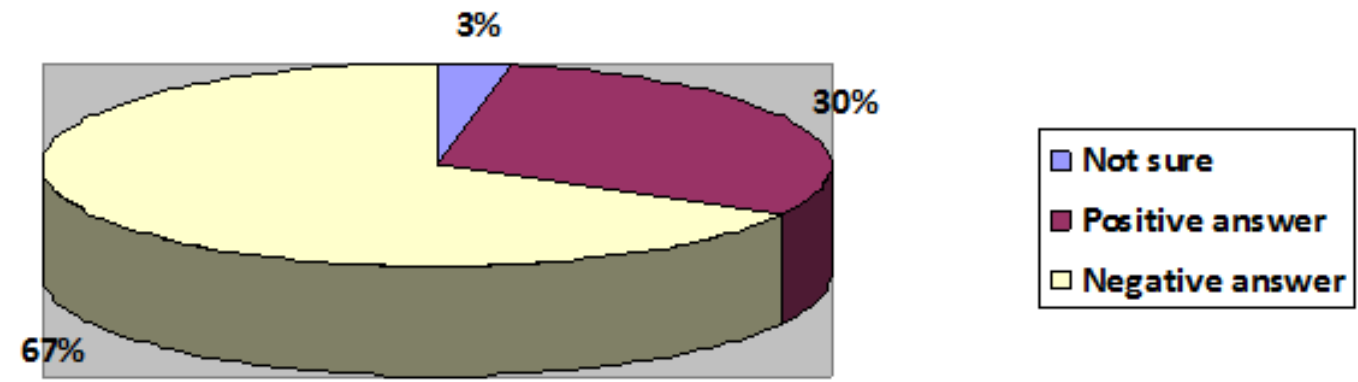

\section{Figure1: Survey Findings on Students' Satisfaction with the Quality of Social, Cultural and Humanitarian Education}

In physical terms, $3 \%$ are not sure, but the majority are negative (67\%). Such a result can be explained by:

- a robust pragmatic attitude towards the choice of specialisation;

- difficulties in preparing professional sociologists;

- a need to promote sociologists as a "brand" in the labour market.
Answers to the question: "What do you wish to improve in education delivery?" are evident. The $\mathrm{SCH}$ classes should develop competencies like critical thinking, communication, knowledge application, and self-reflection (arranged in decreasing priority order).

The study shows significant differences between the real and required quality of university $\mathrm{SCH}$ education (Table 1).

\begin{tabular}{|c|c|c|}
\hline Differentiation Criteria & Actual Quality & Required Quality \\
\hline $\begin{array}{l}\text { Support Materials and } \\
\text { Equipment }\end{array}$ & Sufficient Background & Insufficient Background \\
\hline Status & Middle-Low & High \\
\hline Programme Outline & Collateral & $\begin{array}{l}\text { Same as Science Programme } \\
\text { Outline }\end{array}$ \\
\hline Teaching Paradigm & Society-Human & Human $\leftrightarrow$ Society $\leftrightarrow$ Identity \\
\hline List of Subjects & $\begin{array}{l}\text { Narrow List of Compulsory } \\
\text { Subjects }\end{array}$ & $\begin{array}{l}\text { Expanded List } \\
\text { Recommended Subjects }\end{array}$ \\
\hline Priority Approach to Teaching & $\begin{array}{l}\text { Knowledge-Oriented } \\
\text { Approach }\end{array}$ & System Approach \\
\hline Core Competences to Shape & General Cultural Competences & $\begin{array}{l}\text { Social and Humanitarian } \\
\text { Competences }\end{array}$ \\
\hline
\end{tabular}

Universities may want to utilise the Elabuga education model to raise the quality of $\mathrm{SCH}$ education to a required standard. This model provides for the following stepwise actions:

Scholars and practitioners suggest utilising an education form in which students enter into interaction with real processes and phenomena. Hence, the role of higher education is to place students in socio-cultural and professional contexts. In the case of $\mathrm{SCH}$ education, disciplines should be linked together and follow the principle of socio-cultural conformity (follow 
social, cultural and professional trends) (Levitz, 2013).

To improve the status of $\mathrm{SCH}$ education, both the government and business must recognise its significance. In addition to this, the universities must ensure the disclosure of philosophical, methodological and action-oriented sides of $\mathrm{SCH}$ education.

The findings demonstrate a positive effect of the Elabuga model on the quality of $\mathrm{SCH}$ education (Table 2).

Table 2: The Quality of Students Learning Humanities, Social and Cultural Studies Before and After the Elabuga Model

\begin{tabular}{|c|c|c|c|}
\hline Competency Level & $\begin{array}{l}\text { Control Group } \\
\text { (400 students) }\end{array}$ & $\begin{array}{l}\text { Experimental Group } \\
\text { (390 students) }\end{array}$ & $\begin{array}{l}\text { Difference, } \\
\text { in \% }\end{array}$ \\
\hline \multicolumn{4}{|c|}{ Ascertaining Experiment } \\
\hline High & 44 students ( $11 \%)$ & 47 students (12\%) & $1 \%$ \\
\hline Average & 252 students (63\%) & 248 students (61\%) & $2 \%$ \\
\hline Low & 104 students (26\%) & 75 students ( $27 \%)$ & $1 \%$ \\
\hline \multicolumn{4}{|l|}{ Teaching Experiment } \\
\hline High & $\begin{array}{l}52 \text { students } \\
(13 \% \text {, gain }-2 \%)\end{array}$ & $\begin{array}{l}82 \text { students } \\
(21 \% \text {, gain }-9 \%)\end{array}$ & $7 \%$ \\
\hline Average & $\begin{array}{l}272 \text { students } \\
(68 \% \text {, gain }-5 \%)\end{array}$ & $\begin{array}{l}281 \text { students } \\
\text { (72\%, gain - } 11 \%)\end{array}$ & $6 \%$ \\
\hline Low & $\begin{array}{l}76 \text { students } \\
\text { (19\%, loss - } 7 \%)\end{array}$ & $\begin{array}{l}27 \text { students } \\
(7 \% \text {, loss }-20 \%)\end{array}$ & $-13 \%$ \\
\hline
\end{tabular}

Thus, the portion of students with a high competency level grew $9 \%$ in the experimental group and $2 \%$ in the control group. The portion of students with an average level grew by $11 \%$ and $5 \%$, respectively. In the low-level competency group, the number of students dropped by $20 \%$ and $7 \%$, respectively.

This progress suggests the appearance of special personal qualities in students alongside a new vision of professional worth that refers to the ability to solve consumer problems in the most effective and socially safe manner. Moreover, a new vision of professionalism refers to abilities, such as fostering socially oriented needs in clients and producing attractive services. To develop such professional qualities, universities build their education strategies around economic, socio-cultural, linguistic, and crosscultural competencies. In the climate of globalisation, cross-cultural and communication competencies gain in relevance. Hence, $\mathrm{SCH}$ education becomes more than a necessary addon - it becomes a prerequisite of professional competence development.

\section{Discussion}

Findings from this research are not exclusive of further clarification, specification and extension with educational applications. The Oxford Brookes University (UK) attaches great importance to fundamental and all-around humanitarian education - students may study history, philosophy, sociology, languages, theology, art history, politics and international relations, communication, culture and media studies, modern philosophy, etc. In the Massachusetts Institute of Technology (USA), $25 \%$ of curriculum disciplines are linked to humanities and socio-cultural studies and are mostly practice-oriented. In the Kazan Federal University (Russia), general $\mathrm{SCH}$ disciplines are compulsory and special courses are elective.

Most Western European and Russian researchers admit that students have to learn a wide range of related disciplines to gain better competences (Long, 2013; Vyazemsheva, 2016). The style of delivering $\mathrm{SCH}$ education should contribute to the formation of general cultural competencies (Lönnblad \& Vartiainen, 2012) and 
take into account the features of the future profession (Lönnblad \& Vartiainen, 2012; Levenson, 2016). Western European researchers attach more importance to physical infrastructure and financial support compared to Russian researchers (Levitz \& Belkin, 2013). They also give prominence to practical orientations of teaching (Long, 2013; Levenson, 2016), to general and humanitarian, rather than social and philosophical, education (Rickmann, 2017), and to the adaptation of $\mathrm{SCH}$ education programmes to profession-specific obligations (Levenson, 2016; Kitova, 2018). By contrast, Russian researchers emphasise the importance of sociophilosophical and patriotic education (Levenson, 2016; Yeralina, 2017).

The above suggestions contribute to the improvement of SCH education quality, although many thereof are somehow sketchy. The objective and subjective circumstances, as well as steps towards incorporating these suggestions into educational contexts, are not fully disclosed. Russian researchers should pay more attention to the physical infrastructure and financial support, as well as to the practical orientations of $\mathrm{SCH}$ disciplines. At the same time, Western European researchers should move in philosophical, sociological, cultural directions.

The Elabuga model of education quality improvement applies to a limited range of contexts. This necessitates recommendations on the application. The outlined competencies are not ultimate; the list of recommended disciplines is not complete and does not into account the possible social requirements for education. The directions for future research may involve the updates to the $\mathrm{SCH}$ education model for the period of up to 2030, new competencies to form and specific recommendations for managing the reforming of $\mathrm{SCH}$ education.

The findings are reliable due to relevant methodology and information sources. Meanwhile, an online platform which is known as Coursera becomes increasingly popular. The platform represents a space in which iconic universities (Stanford, Wharton, Princeton) post free courses on various topics, from Art and
Healthcare to Business, Physics and Statistics. Even though all courses are free, users can pay $\$ 40$ for a training certificate.

Thus, the portion of students with a high competency level grew $9 \%$ in the experimental group and $2 \%$ in the control group. The portion of students with an average level grew by $11 \%$ and 5\%, respectively. In the low-level competency group, the number of students dropped by $20 \%$ and $7 \%$, respectively.

This progress suggests the appearance of special personal qualities in students alongside a new vision of professional worth that refers to the ability to solve consumer problems in the most effective and socially safe manner. Moreover, a new vision of professionalism refers to abilities, such as fostering socially oriented needs in clients and producing attractive services. To develop such professional qualities, universities build their education strategies around economic, socio-cultural, linguistic, and crosscultural competencies. In the climate of globalisation, cross-cultural and communication competencies gain in relevance. Hence, $\mathrm{SCH}$ education becomes more than a necessary addon - it becomes a prerequisite of professional competence development.

\section{Discussion}

Findings from this research are not exclusive of further clarification, specification and extension with educational applications. The Oxford Brookes University (UK) attaches great importance to fundamental and all-around humanitarian education - students may study history, philosophy, sociology, languages, theology, art history, politics and international relations, communication, culture and media studies, modern philosophy, etc. In the Massachusetts Institute of Technology (USA), $25 \%$ of curriculum disciplines are linked to humanities and socio-cultural studies and are mostly practice-oriented. In the Kazan Federal University (Russia), general SCH disciplines are compulsory and special courses are elective.

Most Western European and Russian researchers admit that students have to learn a wide range of related disciplines to gain better 
competences (Long, 2013; Vyazemsheva, 2016). The style of delivering $\mathrm{SCH}$ education should contribute to the formation of general cultural competencies (Lönnblad \& Vartiainen, 2012) and take into account the features of the future profession (Lönnblad \& Vartiainen, 2012; Levenson, 2016). Western European researchers attach more importance to physical infrastructure and financial support compared to Russian researchers (Levitz \& Belkin, 2013). They also give prominence to practical orientations of teaching (Long, 2013; Levenson, 2016), to general and humanitarian, rather than social and philosophical, education (Rickmann, 2017), and to the adaptation of $\mathrm{SCH}$ education programmes to profession-specific obligations (Levenson, 2016; Kitova, 2018). By contrast, Russian researchers emphasise the importance of sociophilosophical and patriotic education (Levenson, 2016; Yeralina, 2017).

The above suggestions contribute to the improvement of SCH education quality, although many thereof are somehow sketchy. The objective and subjective circumstances, as well as steps towards incorporating these suggestions into educational contexts, are not fully disclosed. Russian researchers should pay more attention to the physical infrastructure and financial support, as well as to the practical orientations of $\mathrm{SCH}$ disciplines. At the same time, Western European researchers should move in philosophical, sociological, cultural directions.

The Elabuga model of education quality improvement applies to a limited range of contexts. This necessitates recommendations on the application. The outlined competencies are not ultimate; the list of recommended disciplines is not complete and does not into account the possible social requirements for education. The directions for future research may involve the updates to the $\mathrm{SCH}$ education model for the period of up to 2030, new competencies to form and specific recommendations for managing the reforming of $\mathrm{SCH}$ education.

The findings are reliable due to relevant methodology and information sources. Meanwhile, an online platform which is known as Coursera becomes increasingly popular. The platform represents a space in which iconic universities (Stanford, Wharton, Princeton) post free courses on various topics, from Art and Healthcare to Business, Physics and Statistics. Even though all courses are free, users can pay $\$ 40$ for a training certificate.

\section{Conclusion}

The key purpose of the current research was to examine the quality of $\mathrm{SCH}$ education in modern universities and suggest measures for its improvement. The findings suggest that $67 \%$ of Russian students are unsatisfied with the quality of $\mathrm{SCH}$ education. Respondents consider humanities, social and cultural studies as disciplines that enable the development of critical thinking and communication competence in addition to profession-specific competencies. The Elabuga education model allows improving the quality of $\mathrm{SCH}$ education, as evidenced by its implementation in other universities within the country. With this model, the portion of students with high competency level grew $7 \%$, while the portion of low-quality students dropped by $13 \%$. Improving the quality of $\mathrm{SCH}$ education can be achieved in various ways. First, it is necessary for educators to understand the importance of these disciplines. Secondly, it is necessary to revise the curricula of universities in order to find out whether or not social research has a sufficient place in education. If not, make the necessary changes. Thirdly, before the revision of the entire curriculum, one can introduce additional free courses for students interested in these disciplines. SCH teachers may want to apply this model in their educational setting.

Given that educational standard is not a goal but a suggestion, the Elabuga education model seeks to make the most of its potential for variation and restructuring. Educational standards are not necessarily clean-cut, as the education sphere should be one step ahead of the labour market. Such a tendency is promoted by the prospects of social development, social demands and the world trends in education. 


\section{References}

Abeles, T.P. (2011). The Future of the University (review). On the Horizon, 4, 239-244. https://doi.org/10.1108/10748121111186 305

Akimova, I., Chernysheva, A., Motorina, I., \& Popova, A. (2019, February). SocioCultural Transformations of the Information Society as Factors in the Formation of the Personality of the Student of a Technical University. In International Conference Communicative Strategies of Information Society (CSIS 2018). Atlantis Press.

Ashmarina, S. I., Kandrashina, E. A., Izmailov, A. M., \& Mirzayev, N. G. (2020). Gaps in the System of Higher Education in Russia in Terms of Digitalisation. In Digital Transformation of the Economy: Challenges, Trends and New Opportunities (pp. 437-443). Springer, Cham.

Barber, M., Donnelly, K., \& Rizvi, S. (2013). An Avalanche is Coming: Higher Education and the Revolution Ahead. London: Institute for Public Policy Research.

Berglund, P., Dannetun, P., Chan, W. L., Gold, J., Han, S., Hansson, H., ... \& McInerney, G. (2019). Linking Education and Research: A Roadmap for Higher Education Institutions at the Dawn of the Knowledge Society. Preprints, https://doi.org/10.20944/preprints20190 4.0195.v1

Bouvier, A. (2012). Let's Prepare the Education System of 2030. [Préparons l'école de 2030]. Futuribles: Analyse et Prospective, 388, 51-72.

Calhoun, C. (2005). The Promise of Public Sociology. British Journal of Sociology, 56(3), 355-363. https://doi.org/10.1111/j.14684446.2005.00065.x

During, S. (2004). Cultural Studies: A Critical Introduction. Routledge: London

European Commission (2003). Measures to Improve Higher Education, Research
Relations in Order to Strengthen the Strategic Basis of the ERA (pp. 192-206).

Fadel, Ch. (2012). The Education and Human Capital Requirements Roundtable: Exploring Approaches to Lifelong Learning from the 21st century. N. Y.: McGraw Hill Research Foundation.

Jovchelovitch, S. (2019). Knowledge in Context: Representations, Community and Culture. Routledge: London

Kitova, E.T. (2018). Humanisation and Humanitarisation of Engineering Education. Advances in Intelligent Systems and Computing, 677, 61-67.

Levenson, T. (2016). Experience in Teaching Humanities and Social Studies in the US Engineering and Technology Universities. Retrieved on 23 June 2019 from, http://ritworld.com/specialisty-iz-sshapodelilis-opytom-prepodavaniyagumanitarnyx-disciplin-v-texnicheskixvuzax/

Levitz, J., \& Belkin, D. (2013). Humanities Fall from Favour. Retrieved on 23 June 2019 from, http://inosmi.ru/world/20130609/209841 655.html.

Long, M. (2013). The Future of Learning. A Report Sharing the Harvard Graduate School of Education Future of Learning Course, 19. Retrieved on 23 June 2019 from http://www.stjohnscollege.co.za/pdfs/Ma rgot\%20Long_Harvard\%20Report\%20201 3.pdf

Lönnblad, J, \& Vartiainen, M. (2012). Future Competencies - Competencies for New Ways of Working. University of Turku. Retrieved on 23 June 2019 from http://futurex.utu.fi/julkaisut_Future_Co mpetences.pdf.

Naz, S. (2019). Impact of Globalisation on Higher Education in Pakistan: Challenges and Opportunities. International Journal of Innovation in Teaching and Learning 
(IJITL), 2(2).

http://dx.doi.org/10.35993/ijitl.v2i2.363

Piirainen, K.A., Andersen, A.D., \& Andersen, P.D (2016). Foresight and the Third Mission of Universities: The Case for Innovation System Foresight. Foresight, 18(1), 24-40. https://doi.org/10.1108/FS-04-2014-0026

Pohoryles, R. J., \& Schadauer, A. (2009). What Future for the European social sciences and humanities? Innovation: The European Journal of Social Science Research, 22(2), 147-187.

https://doi.org/10.1080/13511610903112 747

Readings, B. (1995). The university without culture? New Literary History, 26(3), 465492.

Reynolds, M. (2019). Culturally Relevant (Teacher) Education: Teachers Responding through $\mathrm{Va}$ in the Intercultural Space of Pasifika Education. New Zealand Journal of Educational Studies, 54(1), 21-38. https://doi.org/10.1007/s40841-01900128-1

Rickmann, M. (2017). Education in the Framework of Sustainable Development Goals: Objectives of Education (pp. 62). Paris: UNESCO.

Rubtcova, M., \& Pavenkov, O. (2019). Pedagogical Support of the Development of Humanitarian Competence of Students-Future Specialists in Public Relations. In ACN-International Conference on Recent Developments in Social Science and Business Management
(ICRDSSBM). Bangalore, Karnataka, India, 18th-20th January.

Teichler, U. (2003). The Future of Higher Education and the Future of Higher Education Research. Tertiary Education and Management, 9(3), 171-185. https://doi.org/10.1080/13583883.2003.9 967102

Toffler, A. (2003). Future Shock (pp. 557). Moscow: AST Publishing House.

Vyazemsheva, A.A. (2016). The USA Experts Shared Their Experience in Teaching Humanities and Social Studies in Engineering and Technology Universities. Retrieved on 23 June 2019 from, http://ritworld.com/specialisty-iz-sshapodelilis-opytom-prepodavaniyagumanitarnyx-disciplin-v-texnicheskixvuzax/.

Webb, M. J. (2008). Humanities and Social Science Courses in Undergraduate Engineering Curricula: The Case of the Arabian Gulf. European Journal of Engineering Education, 33(3), 367-380. https://doi.org/10.1080/03043790802090 216

Yeralina, E. (2017). Analysis and Prospects of Developing Higher Education as a Key Factor of Economic Development (Comparative analysis). Journal of Advanced Research in Law and Economics, 8(2), 670-678.

\section{Acknowledgements}

This article is supported by a state grant allocated to the Kazan (Volga region) Federal University to boost its competitiveness among the world's leading research learning centres. 